\title{
A Competitive Analysis of East African Cement Companies using the High Performance Organisation Framework
}

Evans Makini Osano

Maastricht School of Management, The Netherlands

André de Waal

HPO Center, The Netherlands

\begin{abstract}
Sub-standard infrastructure is one of the most significant challenges for economic development in East Africa. Specifically, the availability of affordable, locally produced cement is critical to infrastructural and economic development and job creation in the region. Thus, it is critical for cement companies to achieve better operational and financial results so they can satisfy the need for higher-quality cement for infrastructure projects and to deal with increasing environmental issues. In this article we evaluate, using de Waal's high performance organisations (HPO) framework, the quality of three cement companies in Kenya and Tanzania to identify improvements these companies can make to their internal organisation and operations so they can achieve better financial and operational results. The research results indicate that whilst all three companies were yet to achieve HPO status, the best performing company with the highest HPO score also had the best financial performance over the past 10 years. The research also resulted in a series of recommendations on the basis of the weaknesses identified in the cement companies.
\end{abstract}

Keywords: High-Performance Organisations; Cement Industry; Kenya; Tanzania; Performance Assessment; HPO

Received: 1 May 2020

ISSN 2056-757X

Revised: 10 August 2020

Accepted: 30 Sept 2020

https://doi.org/10.18646/2056.74.20-032 


\section{Introduction}

Sub-standard infrastructure in East Africa has been a major impediment to regional economic development and negatively impacts the quality of life of the residents in the region (Gregory and Sovacool, 2019). A number of studies, notably Kenya Association of Manufacturers (2006), Ministry of Trade and Industry (2007), World Bank (2016) and UNIDO (2001), identified inadequate infrastructure as the most significant challenge for economic development and creating better livelihoods in Kenya and Tanzania. The availability of affordable locally produced cement is critical to cheaper housing, and more infrastructural and economic development and job creation. Cement is a key ingredient in the construction sector, particularly for infrastructure development. Thus, it is critical for cement companies to achieve better operational and financial results so they can satisfy the increasing demand for higher-quality cement for infrastructure projects. At the same time, cement companies have to deal with increasing environmental issues. Cement production consumes large quantities of raw materials and energy and is therefore a significant contributor to climate change, accounting for approximately eight percent of global man-made carbon dioxide (Miller et al., 2018).

The study described in this article focuses on evaluating the quality of cement companies so it becomes clear where these organisations can apply improvements in their internal organisation and operations to better deal with the environmental issues while at the same time achieving better financial and operational results. As evaluation tool, de Waal's HPO Framework (de Waal, 2007, 2012) was used, as this framework is a scientifically validated conceptualization of high performance organisations (HPOs) which highlights the factors that help companies strengthen their internal organisation, thus making them able to achieve higher performance (Do and Mai, 2020). In this respect, the HPO is defined as an organisation that achieves financial and non-financial results that are significantly better than those of its peer group over a period of five years or more, by focusing in a disciplined way on that what really matters to the organisation (de Waal, 2012, p.5). In many previous studies it has been shown that the higher a company scores on the HPO Framework, the better its performance (de Waal, 2012, 2020; de Waal and Goedegebuure, 2017). Therefore the aim of this study was to evaluate the HPO scores of selected cement companies and subsequently compare their internal organisation, operation and culture to identify the differences which make one cement company perform better than the other.

As an insufficiently developed infrastructure is a regional problem in East Africa, as a research population cement companies were selected from two neighbouring countries in the region, Kenya and Tanzania. It has to be noted that because of confidentiality reasons: (a) the companies have been made anonymous, and (b) the research took place eight years ago and this description had to wait until the financial results given in this article are no longer representative of the current situation of the case companies (this however in itself does not affect the relevance of the study and the mechanisms studied). The study has both theoretical and practical contributions to make.

International Journal of Management and Applied Research, 2020, Vol. 7, No. 4 
Theoretically, the research results will add to the still rather limited literature on management, high performance and HPOs in Africa (Areneke et al., 2019). Practically, the research results show that the HPO Framework can be used to improve the regional cement companies; this will offer the opportunity for other African cement companies and potentially also other African manufacturing companies in the region to improve themselves, using the HPO Framework.

The remainder of this article is structured as follows. In the next section the cement industry in Kenya and Tanzania are introduced. Subsequently, the HPO Framework is described after which the research approach is given. This is followed by an overview of the research results and analysis thereof. The article ends with a conclusion, the limitations to the research, and opportunities for future research.

\section{Study Background}

This section is divided into two parts. The first part describes the cement industry in Kenya and Tanzania, two countries located in East Africa. The second part discusses the HPO Framework and its application in the African context.

\subsection{The cement industry in Kenya and Tanzania}

Cement industry growth in both Kenya and Tanzania has been strong over the last ten years due to resurgence in the building and construction sectors both locally and in the regional market. Kenya is self-sufficient in cement production with a small surplus that is exported regionally. The cement sector was the second fastest growing in Kenya generating a growth rate of 12.7 percent in 2013. The construction sector accounted for 4.4 percent of Kenya's GDP in 2013. In 2013, there were six cement companies in Kenya with a combined milling capacity of 7.2 million metric tons per annum. Production stood at 5.1 million tonnes against local consumption of 4.3 million tonnes in 2013. Three cement manufacturing companies were listed on the Nairobi Stock Exchange with a combined market capitalization of US\$1.1 billion (Ministry of Trade and Industry, 2014).

Tanzania, in contrast to Kenya, was not self-sufficient in cement although planned capacity increases would more than meet the current shortfall. In 2013, cement consumption stood at 3.4 million tons against production of 2.3 million tones with the shortfall met by imports. The construction sector accounted for 6.5 percent of GDP in 2013, with growth rate averaging 9.8 percent between 2004 and 2013. The sector was a beneficiary of increased spending on infrastructure by the Tanzanian government and donor agencies in recent years. The country had three cement companies, two of which were listed on the Dar es Salaam Stock Exchange (Ministry of Industry and Trade, 2014).

The research was conducted at three cement companies, two in Kenya and one in Tanzania. These were Company KA and Company KB, both in Kenya, and Company TC in Tanzania. As stated before the companies had to be made anonymous, and

International Journal of Management and Applied Research, 2020, Vol. 7, No. 4

$$
-456-
$$


although they could still be traceable (as there are not many cement companies in both countries), using synonyms indicates that their current situation cannot and should not be compared to that during the time of the research. The three companies represented at the time of the research fifty percent of the cement companies in Kenya and Tanzania and accounted for over four percent of the cement produced in both countries in 2013.

\subsection{High Performance Organisations}

A High Performance Organisation (HPO) is defined as "an organisation that achieves financial and non-financial results that are exceedingly better than those of its peer group over a period of time of five years or more, by focusing in a disciplined way on that what really matters to the organisation" (De Waal, 2012, p.5). Non-financial results relate to customer satisfaction, customer loyalty, employee loyalty and quality of products and services. As the evaluation mechanism for the study the de Waal HPO Framework was chosen because, as Do and Mai (2020, p. 305) stated, "across the HPO literature, we found only the HPO framework developed by de Waal (2012) as an example of scientifically validated conceptualization of HPO." Another reason to use the HPO Framework is that is has been applied quite extensively in the African context (de Waal, 2012; de Waal and Chachage, 2011; de Waal and Mulimbika, 2017; de Waal and Olale, 2019; Habyarimana and de Waal, 2020; Honyenuga et al., 2014, 2019). The factors and characteristics of the HPO Framework were determined during a multiyear study consisting of two phases. In the first phase, a literature review of 290 studies into high performance was undertaken to identify common characteristics or themes explaining HPOs (de Waal, 2007). The analysis initially identified 189 potential characteristics which, using a questionnaire distributed to profit and non-profit companies worldwide and subsequent statistical analysis, were reduced to 35 characteristics in five factors. These factors basically make up an HPO and have a direct positive relation with competitive performance (de Waal, 2012).

The five factors are Management Quality, Openness and Action Orientation, Longterm Orientation, Continuous Improvement and Renewal, and Employee Quality (see the Appendix for the detailed HPO characteristics). HPO factor Management Quality is primarily focused on leadership, managers being sound role models who nurture and inspire trust, respect and enthusiasm, and are performance-oriented both in their ability to make decisions and to execute them. HPO factor Openness and Action Orientation encourages dialogue and change in the organisation, essential for creating openness, renewal and innovativeness. Openness also fostered innovation by improving the flow and frequency of information implying that promising ideas in $R \& D$, product development, strategy and marketing are aired and refined quickly. HPOs continuously strive for Continuous Improvement and Renewal to create new sources of competitive advantage through new product development, innovation, simplification and improvement in processes and gaining mastery in key competences. Striving for continuous improvement underlies initiatives such as Six Sigma and Total Quality Management. HPO factor Employee Quality requires that an organisation must not only have good people who are energized and focused on achieving extraordinary

International Journal of Management and Applied Research, 2020, Vol. 7, No. 4 
performance but that they are also able to continuously update their skills. Finally, HPO factor Long-term Orientation ensures that the organisation maintains mutually beneficial enduring long-term relationships and partnerships with stakeholders and is socially responsible. In fact, HPOs are characterized by their corporate social responsibility (CSR) awareness, also referred to as people, profit and planet (de Waal and Orcotoma Escalante, 2008). In this respect, de Waal and Orcotoma Escalante (2008) identified seven CSR aspects related to HPO characteristics and verified these at two mining companies in Peru, demonstrating that the mining company with the strongest financial performance also had the highest CSR scores.

An organisation can evaluate its current performance compared to the highperformance level - between 8.5 and 10 on a scale of 1 to 10 (de Waal, 2012) - and identify challenges and possible improvements on the route to high performance by conducting an HPO diagnosis. The HPO diagnosis process starts with management and employees completing the HPO Questionnaire, which consists of statements based on the $35 \mathrm{HPO}$ characteristics. Respondents rate their organisation on a scale of 1 (not at all) to 10 (very much so) on these statements. The individual scores are averaged to provide scores on the HPO factors for the complete organisation. These average scores indicate which HPO factors and characteristics the company needs to improve in order to become an HPO, the organisation drafts improvement actions for these factors and characteristics which then are incorporated in an HPO transformation plan.

\section{Research Approach}

The aim of the research was to compare the cement industry in Kenya and Tanzania, to identify which particular HPO characteristics made a cement company perform strongly and whether there was a difference between these identified characteristics across the two countries. The financially best and worst performing cement companies in each country at the date of the research were asked to participate. The worst performing company in Tanzania declined to participate and therefore was not included in the research. Primary data on the companies was collected by use of the HPO Questionnaire, to determine the overall and individual scores on the five HPO factors and 35 HPO characteristics. Initially the HPO Questionnaire was distributed through the internet; however, the response rate was very low, mainly due to limited internet access for many potential respondents. Consequently, the questionnaire was distributed manually to the participating companies. The lead researcher made field visits to all these locations and undertook the distribution of the questionnaires and interviews with the CEO and other management team members in the companies. The questionnaire was distributed over a stratified sample aimed at targeting the functional areas of the companies including manufacturing, distribution/logistics, marketing and finance, and to both managers and employees. This was achieved through the support of the human resources departments of these organisations. The researcher employed a research assistant to enter the completed questionnaires into the web-based database system. Table 1 provides information on the response per company.

International Journal of Management and Applied Research, 2020, Vol. 7, No. 4

$$
-458-
$$


A Competitive Analysis of East African Cement Companies using the High Performance Organisation Framework

Table 1: Information on the participating cement companies

\begin{tabular}{lccc}
\hline Company information & KA & KB & TC \\
\hline Country & Kenya & Kenya & Tanzania \\
Number of employees & 1,300 & 700 & 300 \\
Number of plants & 1 & 3 & 2 \\
Capacity (million tons) & 3.25 & 2.90 & 3.15 \\
Market share (\%) & 16 & 24 & 42 \\
Number of questionnaires & 45 & 70 & 50 \\
Number of respondents & 34 & 60 & 42 \\
Response rate (\%) & 76 & 86 & 84 \\
Response rate (as \% of employees) & 3 & 9 & 14 \\
\hline
\end{tabular}

A total of 165 questionnaires were distributed with a response rate of 82 percentage, split down as 76, 86 and 84 percentage respectively for Company KA, Company KB and Company TC. This response rate was relatively high as the lead researcher was able to solicit the support of the top management in the data collection.

The questionnaires were administered in the English language and were not translated into the local languages. The choice of English language was mainly on account of its widespread use in Kenya and Tanzania, particularly in the corporate world.

Subsequently, in-depth interviews with managers at the three companies helped to ascertain the reasons for the various HPO scores. At Company KA four management staff in the manufacturing, procurement and human resources departments were interviewed. At Company KB interviews were held with the deputy chief executive at different points in the research process to obtain a better understanding of the industry dynamics and Company KB's relative strengths and positioning. At Company TC, three management staffs from the human resources and manufacturing departments were interviewed.

Organisational performance was determined using export performance and company performance over a period of time. This involved reviewing secondary data from sources such as the National Bureau of Statistics in Kenya and Tanzania, Ministries of Trade and Industry, company specific data (where available) as well as industry data.

\section{Research Results and Analysis}

This section first provides the results of the HPO Questionnaire and the financial results of the companies, and then discusses these results in-depth using information collected during the interviews.

\subsection{Scores}

Table 2 summarizes the HPO scores for the three participating cement companies, while Figure 1 provides a graphical representation of these scores.

International Journal of Management and Applied Research, 2020, Vol. 7, No. 4 
A Competitive Analysis of East African Cement Companies using the High Performance Organisation Framework

Table 2: HPO scores for the three East Africa Cement Companies

\begin{tabular}{lccc}
\hline HPO factors & Company KA & Company KB & Company TC \\
\hline Management Quality & 6.4 & 8.3 & 7.3 \\
Openness and Action Orientation & 5.9 & 7.6 & 6.6 \\
Long-term Orientation & 7.0 & 8.5 & 7.7 \\
Continuous Improvement & 6.5 & 8.0 & 7.5 \\
Employee Quality & 6.9 & 8.2 & 7.6 \\
Average HPO score & $\mathbf{6 . 6}$ & $\mathbf{8 . 1}$ & $\mathbf{7 . 3}$ \\
\hline
\end{tabular}

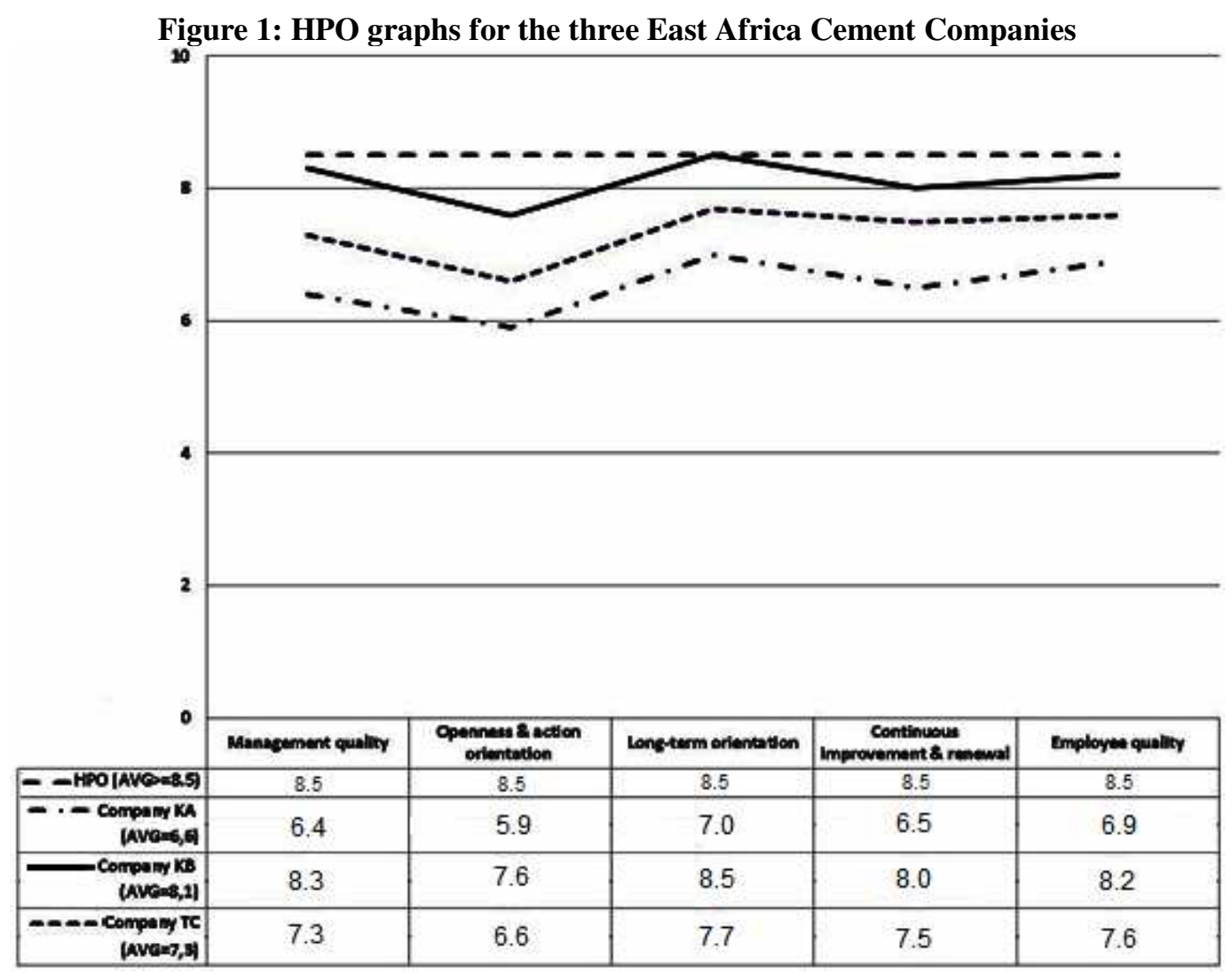

The financial performances of the three companies over the past 10 years were reviewed, to analyze margins and growth in profitability and shareholder value. As the cement sector is a cyclical industry with a cycle time of 5-8 years, a 10-year period was therefore selected to ensure that performance of the companies did not just reflect a single business cycle. The average change in net profits was a computed as the percentage change in net profits between the financial year ending 2013 and the year ending 2003, divided by 10 (number of years during the period). Market capitalization was used as a proxy for shareholder value. The shareholder value (\%) is the change in market capitalization between 2003 and 2013 divided by 10. The results are given in Table 3.

International Journal of Management and Applied Research, 2020, Vol. 7, No. 4

$$
-460-
$$


A Competitive Analysis of East African Cement Companies using the High Performance Organisation Framework

Table 3: HPO score and financial performance of cement companies

\begin{tabular}{lccc}
\hline Indicators & Company KA & Company KB & Company TC \\
\hline Average Change in Net Profits p.a. & $-7 \%$ & $129 \%$ & $40 \%$ \\
Shareholder Value p.a. & $2 \%$ & $361 \%$ & $19 \%$ \\
HPO Score & 6.6 & 8.1 & 7.3 \\
\hline
\end{tabular}

Figure 1 shows that the three cement companies share the same HPO profile, that is, the lines in Figure 1 have the same shape. It is thus clear that the three companies operate in the same industry but are of different strengths (i.e. have different HPO scores). Table 3 indicates there is alignment between the HPO scores of the companies and their financial results, i.e. Company KB has the highest HPO score and the best financial results, with Company KA achieving the opposite, and Company TC being in the middle performance-wise.

\subsection{General analysis of the HPO scores}

Maybe characteristically, the interviews at Company KA did not yield much information, as interviewees were not that open. This might not have come as a surprise as Company KA registered poor performance in openness and action orientation. From the interviews it was gathered that frequent management changes particularly at the Chief Executive level - were considered destabilizing to the organisation. It was also felt that decision-making was unduly slow, particularly in regard to non-performers. The slow decision making process may be due to cultural issues. Collectivistic culture such as in Kenyan and Tanzanian societies may slow decision-making as it encourages wide consultations before decisions can be made (Amoako-Agyei, 2009; Hofstede, 1980). And, as Amoako-Agyei (2009) noted, collective solidarity may prevent managers from taking decisive action against nonperformers. Another reason for the slow decision-making process in Company KA is that this is by far the largest organisation of the three cement companies, with more management and therefore decision-making layers.

Company $\mathrm{KB}$ saw its core competence as its ability to continuously improve and innovate. This enabled the company to reduce production costs, serve new markets and extend its product mix. The company was also willing to take calculated risks. In particular, it was proud of its project management skills which enabled it to complete projects on time at substantially lower costs compared to competitors. Company KB had the highest score on the management quality factor. In particular, the respondents rated the company highly on trust, integrity, confidence and results orientation. However, the management did not perform as well on speed in decision-making, decisiveness with regard to non-performers and holding members accountable on results. This suggests that the performance culture had not necessarily permeated the entire organisation, reflecting significant scope for improvement. Company KB's management explained that $\mathrm{KB}$ was a relatively small company, constrained by resources. They were therefore cautious in making decisions and implementing plans, affecting the speed of making decisions. This cautious, slower decision making might also be due to the nature of the industry, which is highly capital intensive and with

International Journal of Management and Applied Research, 2020, Vol. 7, No. 4 
high indebtedness/gearing ratios which would make mistakes costly to the company. This could also explain management's lack of tolerance of mistakes. In theory, this would hinder innovation in the company as making mistakes can be a learning opportunity. Management indicated that innovation was considered more important by the higher management echelons, a feeling which had not been dispersed to other organisational levels. Innovations were mainly around energy efficiency and reduction in the cost of production. Focus was squarely on the production line where line balancing and enhancement were applied to ensure that the over 10,000 pieces of equipment operated optimally.

The plant operations were also broken down to small units and energy consumption at each of these units was closely monitored and appropriate switching sequence applied to reduce big load power consumption. The new production line would also take alternative fuels, particularly at the pre-process level, which facilitated greater energy savings. In 2009, the company won the Kenya Institute of Management Energy Innovation Award and its CEO was awarded Africa's Innovation Leader of the Year Award by the Africa Investor, recognizing the firm's ability at generating new ideas and successfully executing them. In particular, the company was recognized for reducing the cost of manufacturing and building new plants. Many respondents felt that Company KB did not provide a secure workplace, in the sense of being a safe and healthy place to work, for organisational members. Management explained that it had provided an Employee Share Ownership Program (ESOP) for employees and had relatively low employee turnover. However, it did not for instance run a medical and retirement benefits schemes - which may partly explain the low ranking on this attribute.

At Company TC, the interviewees indicated that there was a strong focus on social and environmental management in the company. They also felt that Company TC provided a good working environment for organisational members, and considered the organisation to be performance driven. At the same time, they were of the view that management did not allow for the making of mistakes, which is an essential element in encouraging innovation, which might explain the lower scores compared to Company $\mathrm{KB}$ for innovating products and processes.

\subsection{Comparative analysis of the HPO factors}

The biggest difference in scores between the companies is found in HPO factor Management Quality (1.9 points difference between Company KB and Company KA), closely followed by HPO factor Openness and Action Orientation. Management plays an important role in an organisation; it provides leadership, sets the tone and strategy, creates a conducive environment and inspires the organisation to achieve its objectives. Management also attracts, nurtures talent and motivates employees. It sets the vision, organizes the business, sets a good example and creates an environment with the right incentives for achievement of the organisational goals. This is ultimately reflected in the innovations and continuous improvements that take place in the organisation and the commitment to the long-term goals. Management significantly influences the other

International Journal of Management and Applied Research, 2020, Vol. 7, No. 4 
four characteristics of an HPO and therefore plays a disproportionately large influence in the attainment and maintaining of HPO status. Company KA had the lowest scores of the three companies on the HPO characteristics of Management Quality, which means the respondents of Company KA deemed their management not to be highperformance quality yet, indicating a lot of development was needed in this area. This development of management was going on in the other two companies, thus significantly contributing to the performance of these companies as well-trained management is a success factor for organisations in general (de Waal, 2020) and thus also for African organisations (Douglas et al., 2015; Guo and Bartram, 2019, Tunyia et al., 2019) especially as managerial skills are still in short supply in this area (Barasa et al., 2017).

\subsection{Comparative analysis of HPO factor Openness and Action Orientation}

Openness and action orientation ensures that the good intentions and strategies of management are put into action. By creating an open culture, a healthy dialogue is maintained between management and staff, learning from mistakes is promoted and creativity is nurtured. Action orientation ensures good and timely execution, key in the attainment and maintaining of HPO status. Interestingly, all three companies registered the lowest score on HPO factor Openness and Action Orientation. Further analysis of the results showed that the companies had the lowest scores for the level of dialogue and communication with employees, and for management allowing mistakes. This seems in contradiction with the African culture being highly collectivistic and group-oriented (Hofstede, 1980), thus one would expect that managers in Kenya and Tanzania would be better at dialoguing with employees. There are two possible explanations. First, in a collectivistic culture, "keeping peace" is considered important and people may not be inclined to speak openly, avoiding "rocking the boat". Secondly, in the context of a culture of relatively high power distance, where superiors wield much power and subordinates are relatively passive, people may not want to question authority. At the same time management does not feel compelled to widely consult with staff. There may be a lot of communication but not necessarily dialogue with managers talking a lot to employees instead of having a real conversation, which encompasses an exchange of ideas and opinions on the basis of which the managers make decisions.

\subsection{Comparative analysis of HPO factor Long-term orientation}

The three companies recorded strong scores on most of the HPO characteristics measuring Long-term Orientation. These can be explained in that the three companies had embraced corporate sustainability in their operations, in the shape of elaborate policies and processes aiming at mitigating their environmental impact, including processes to cut energy consumption, and regeneration and reforestation at disused quarries. They also had support programs, particularly in health and education, for the surrounding communities. Other activities included energy efficiency improvement programs, including alternative fuels. The only exception in regard to the high scores was the tenure of management in the companies. In particular, Company KA had as

International Journal of Management and Applied Research, 2020, Vol. 7, No. 4 
many as seven chief executives in the previous seven years, an average of one chief executive per year!

\subsection{Comparative analysis of HPO factor Employee Quality}

Regarding HPO factor Employee Quality, Company KB scored the highest, possibly because the company had, of all the companies, the most elaborate internship and training programs for its employees. In 2013, for instance, 81 students drawn largely from the engineering field benefitted from the internship program. Company KB's internship program played the dual role of empowering the students thus contributing to society and creating a well-filled pipeline of potential new employees. Further, on a yearly basis, at least 20 percent of Company KB's workforce participated in various training programs. This educational effort is very welcome and needed as in general the service delivery in the educational sector in Kenya (and for that matter also in Tanzania) is rather weak (Cheruiyot and Maru, 2013; Hausken and Ncube, 2018).

\subsection{Comparative analysis of the financial results}

Figure 2 gives the operating profit margins of the three cement companies, for the period 2003 - 2013. We have used operating margin percentage as these can be compared well across the companies because the size differences of companies are equalized by the percentages.

Figure 2: Operating profit percentage for the three cement companies

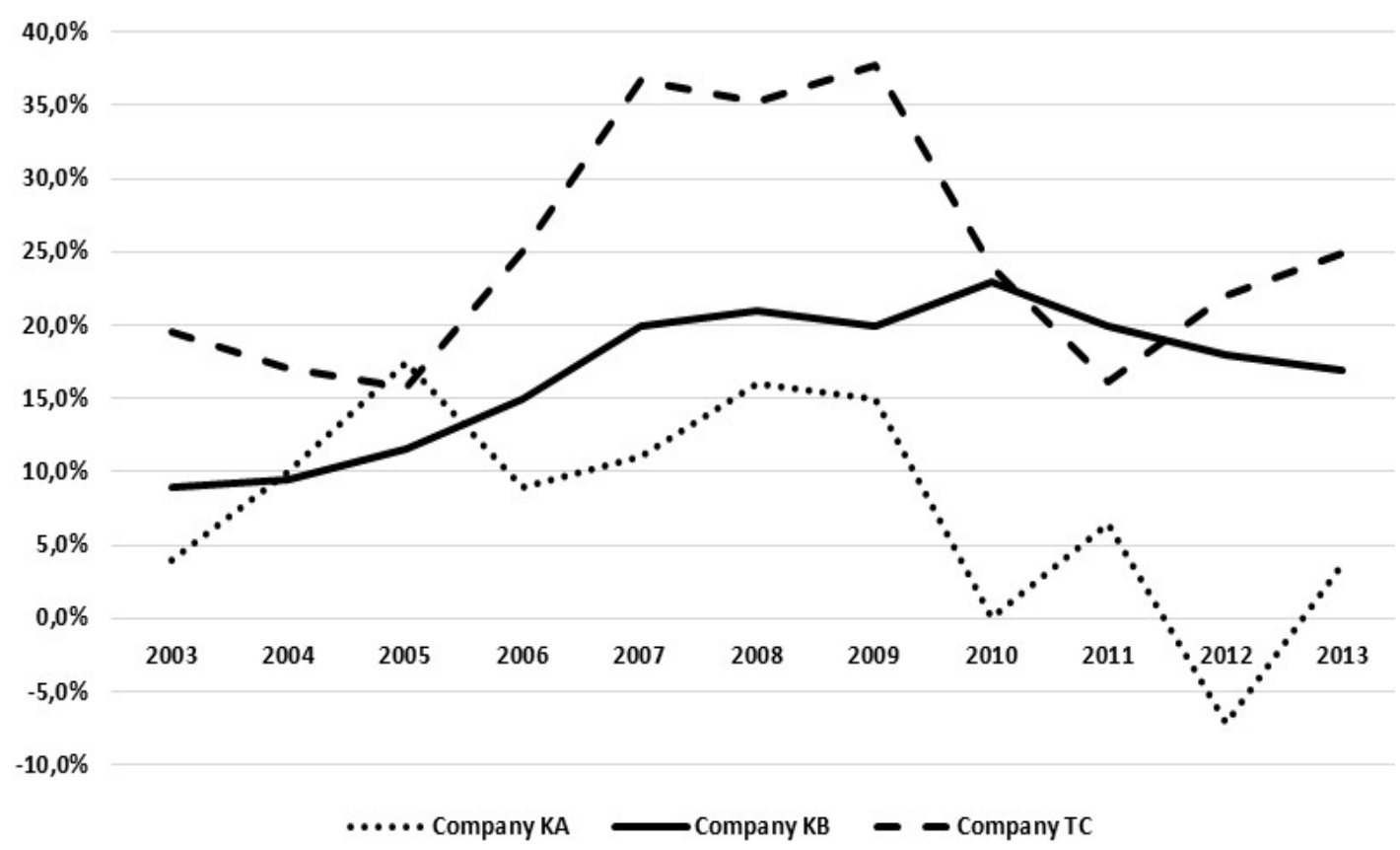

Company KB's operating profit margin improved from 9.0 percent in 2003 to 16.9 percent in 2013, caused by continuous improvements in processes and new

International Journal of Management and Applied Research, 2020, Vol. 7, No. 4 
investments in a state of the art cement plant, diversification into higher margin cement businesses, better cost control, and operational efficiency improvements in the processes. Over a 10-year period the operating margin percentage has steadily improved, reflecting the robust nature of the company. Company $\mathrm{KB}$ was upbeat about its financial prospects for the next ten year period. The financial performance of Company KA over the previous ten years had been mixed with a clear downward trend, as Figure 2 clearly shows. This was partly caused by foreign exchange losses and high operating costs especially in staff costs. For instance, in 2012 staff costs constituted 12 percent of the cost of manufacturing compared to a 5-6 percent average for the other cement companies in the region. Company KA was pessimistic about its financial prospects for the next ten year period as it saw many threats, especially from foreign competitors, potentially hurting its future business and results. The financial performance of Company TC was exceptional, although erratic, over the ten year period in question. The operating margin pattern can be favourably attributed to cement price increases and better cost control, and unfavourably to higher costs caused by the company relying on expensive imported clinker following the upgrade in its milling capacity. Company TC was upbeat about its financial prospects for the next ten year period.

\subsection{Recommendations}

Following the analysis in the previous sections, the following recommendations can be made to the three cement companies to improve or maintain their HPO scores:

- Management Quality - The companies need to design management development plans to improve the skills, behaviours and performance of its managers. It is particularly critical for Company KA which recorded the lowest scores on the HPO factor on management quality. The development plans should especially focus on the development of behaviours in the following areas: decision making and action taking, and dialoguing.

- Openness and Action Orientation - The companies should encourage more openness, including improving the level of dialogue and communication with the employees. In particular, management should be trained to improve its dialoguing and communication skills.

- Long-term Orientation - The companies should invest more time and resources in making their organisations a secure work place for their employees. Specific actions needed include improvements in corporate governance in Company KA where there have been too frequent changes in the top management. Further, Company KB should consider introducing medical and retirement schemes for its employees.

- Continuous Improvement and Renewal - All three companies should focus on simplifying and aligning their organisation processes in order to improve their performance.

- Employee Quality - The three companies have to deal with different issues to improve the quality of their workforce. Company KB and Company KA should make employees accountable for their results. This requires the design and implementation of an appropriate performance management program. In addition,

International Journal of Management and Applied Research, 2020, Vol. 7, No. 4 
Company KA's management needs to inspire its employees to achieve extraordinary results. For Company TC, the focus should be on training and cultural change programs for their employees to become more resilient and flexible.

\section{Conclusion}

The study described in this article set out to evaluate the quality of cement companies in Kenya and Tanzania. The goal was to identify the current strengths and weaknesses of the three companies, so it would become clear where these organisations could apply improvements in their internal organisation and operations to achieve better financial and operational results. As the evaluation tool, de Waal's HPO Framework (de Waal, 2007, 2012) was used. This provided another research goal, namely to evaluate whether there was a relation between the HPO scores and the financial results of the companies. The research results indicate that whilst all three companies were yet to achieve HPO status, Company KB was the best performer with an HPO score close to the HPO status and consistent strong financial performance over the past 10 years. The research also resulted in a series of recommendations on the basis of the weaknesses identified.

There were some limitations to the study. As the cement industry in both Kenia and Tanzania was dominated by a few firms, there was a limited number of potential companies in which to carry out the research. For instance, there were only three cement manufacturing firms in Kenya and three in Tanzania. Future research could expand to the cement industry in other countries, both in Africa and other parts of the world. In addition, the research could be expanded to other industries in Kenya and Tanzania, to possibly achieve generalization of the research findings. Another limitation was that the findings were based on only the managers' views, future research could and should include the views of employees, to get a better and less biased balance in the research results. Also, the research did not look into the effects of the recommendations, i.e. whether cement companies implementing the recommendations would actually perform better. Future longitudinal research could look into that. Future comparative study could go more in-depth in the cement companies themselves, to evaluate whether there are HPO score and financial performance differences between plants and branches. Finally, to evaluate possible cultural differences, it would be useful to replicate the study in West Africa and Southern Africa.

\section{References}

1. Amoako-Agyei E. (2010), "Cross-cultural management and organisational behavior in Africa", Thunderbird International Business Review, Vol. 51, No. 4, pp. 329-339. https://doi.org/10.1002/tie.20270

2. Areneke, G., Yusuf, F., and Kimani, D. (2019), "Anglo-American governance adoption in non-Anglo-American settings: Assessing practitioner perceptions of

International Journal of Management and Applied Research, 2020, Vol. 7, No. 4

$$
\text { - } 466 \text { - }
$$


corporate governance across three emerging economies", Managerial Auditing Journal, Vol. 34, No. 4, pp. 482-510. https://doi.org/10.1108/MAJ-12-2017-1733

3. Barasa, L., Knoben, J., Vermeulen, P., Kimuyu, P. and Kinyanjui, B. (2017), "Institutions, resources and innovation in East Africa: A firm level approach", Research Policy, Vol. 46 No.1, pp. 280-291. https://doi.org/10.1016/j.respol.2016.11.008

4. Cheruiyot, T.K. and Maru, L.C.(2013), 'Service quality and relative performance of public universities in East Africa', TQM Journal, Vol. 25, No. 5, pp. 533-546. https://doi.org/10.1108/TQM-11-2012-0103

5. de Waal, A.A. (2007), "The characteristics of a high performance organisation", Business Strategy Series, Vol. 8 No. 3, pp. 179-185. https://doi.org/10.1108/17515630710684178

6. de Waal, A.A. (2012), What Makes a High Performance Organisation: Five Validated Factors of Competitive Performance that Apply Worldwide, Enfield: Global Professional Publishing.

7. de Waal, A.A. (2020), High Performance managerial Leadership, best ideas from around the world, Santa Barbara: Praeger.

8. de Waal, A. de and Chachage, B. (2011), "Applicability of the high-performance organisation framework at an East African university: the case of Iringa University College", International Journal of Emerging Markets, Vol. 6, No. 2, pp. 148-167. https://doi.org/10.1177\%2F2158244017715672

9. de Waal, A. A. and Goedegebuure, R. (2017), "Investigating the causal link between a management improvement technique and organisational performance: The case of the HPO framework", Management Research Review, Vol. 40, No. 4, pp. 429-450. https://doi.org/10.1108/MRR-03-2016-0058

10. de Waal, A. and Mulimbika, T. (2017), "A comparative analysis of Zambian governmental institutions using the HPO framework", SAGE Open, pp. 1-17. https://doi.org/10.1177\%2F2158244017715672

11. de Waal, A. and Olale, D.A. (2019), "Analyzing the effectiveness of a Kenyan NGO with the HPO Framework", Global Business and Organisational Excellence, Vol. 38, No. 2, pp. 31-42. https://doi.org/10.1002/joe.21908

12. de Waal, A.A. and Orcotoma Escalante, G. (2011), "Does the application of corporate social responsibility support a high performance organisation in achieving better results? The case of mining multinationals in Peru", International Journal of Sustainable Strategic Management, Vol. 3, No. 1, pp. 33-49. https://doi.org/10.1504/IJSSM.2011.040778

13. Do, T. and Mai, N. (2020), "High-performance organisation: a literature review", Journal of Strategy and Management, Vol. 13 No. 2, pp. 297-309. https://doi.org/10.1108/JSMA-11-2019-0198

International Journal of Management and Applied Research, 2020, Vol. 7, No. 4 
14. Douglas, A., Douglas, J. and Ochieng, J. (2015), "Lean Six Sigma implementation in East Africa: findings from a pilot study", TQM Journal, Vol. 27, No. 6, pp. 772780. https://doi.org/10.1108/TQM-05-2015-0066

15. Gregory, J. and Sovacool, B.K. (2019), "The financial risks and barriers to electricity infrastructure in Kenya, Tanzania, and Mozambique: A critical and systematic review of the academic literature", Energy Policy, Vol. 125, pp. 145153. https://doi.org/10.1016/j.enpol.2018.10.026

16. Guo, A.Z. and Bartram, J.K. (2019), 'Predictors of water quality in rural healthcare facilities in 14 low- and middle-income countries', Journal of Cleaner Production, Vol. 237, Article 117836.. https://doi.org/10.1016/j.jclepro.2019.117836

17. Habyarimana, B. and de Waal, A. (2020), "Analyzing An Organisational Change Process Using the HPO Framework: the Case of A Rwandese Bank", International Journal of Management and Applied Research, Vol. 7, No. 2, pp. 120-135. https://doi.org/10.18646/2056.72.20-009

18. Hausken, K. and Ncube, M. (2018), "Service delivery weaknesses within education and healthcare: Applying empirics from Kenya, Uganda, Tanzania, and Senegal", Review of Development Economics, Vol. 22, No. 1, pp. 133-147. https://doi.org/10.1111/rode.12333

19. Hofstede, G. (1980), Culture's Consequences: International Differences in WorkRelated Values, Calfornia: Sage Publications.

20. Honyenuga, B.Q, Tuninga, R.S.J. and Ghijsen, P.W.Th. (2014), "High performance organisations framework as a predictor of organisations performance in the insurance industry in Ghana", Journal of Transnational Management, Vol. 19, No.4, pp. 261-278. https://doi.org/10.1080/15475778.2014.960786

21. Honyenuga, B.Q, Tuninga, R.S.J. and Ghijsen, P.W.Th. (2019), "Management innovation and organisational performance: the mediating role of high performance organisation framework", International Journal of Business and Globalisation, Vol. 22, No. 3, pp. 295-315. https://doi.org/10.1504/IJBG.2019.099296

22. Kenya Association of Manufacturers (2006), Manufacturing in Kenya: Survey of Kenya's Manufacturing Sector, Kenya Association of Manufacturers, Nairobi.

23. Miller, S. A.; John, V. M.; Pacca, S. A. and Horvath, A. (2018), "Carbon dioxide reduction potential in the global cement industry by 2050", Cement and Concrete Research, Vol. 114, pp. 115-124. https://doi.org/10.1016/j.cemconres.2017.08.026

24. Ministry of Industry and Trade (2014), Quarterly Economic Bulletin 2014, Dar Es Salaam: Ministry of Industry and Trade

25. Ministry of Trade and Industry (2007), Master Plan for Kenyan Industrial Development, Nairobi: Ministry of Trade and Industry,.

26. Ministry of Trade and Industry (2014), Economic Survey 2014, Ministry of Trade and Industry, Government of Kenya, Nairobi.

International Journal of Management and Applied Research, 2020, Vol. 7, No. 4

$$
-468-
$$


27. Tunyi, A.A., Agyei-Boapeah, H., Areneke, G. and Agyemang, J. (2019), "Internal capabilities, national governance and performance in African firms", Research in International Business and Finance, Vol. 50, pp. 18-37. https://doi.org/10.1016/j.ribaf.2019.04.009

28. World Bank (2016), Infrastructure for Economic Growth and Shared Prosperity in Kenya: Addressing Infrastructure Constraints, Promoting Economic Growth, and Reducing Inequality, [Online] Available from: https://www.worldbank.org/en/results/2016/07/21/infrastructure-for-economicgrowth-and-shared-prosperity-in-kenya-addressing-infrastructure-constraintspromoting-economic-growth-and-reducing-inequality [Accessed on 14 May 2020].

29. United Nations Industrial Development Organisation (UNIDO) (2001), Tanzania Sustainable Industrial Development and Competitiveness (Analyzing Competitiveness, Strategies, Policies and Action Plan to Accelerate Industrial Development), Austria: UNIDO.

\section{Appendix}

This Appendix provides the detailed scores on the HPOP characteristics for the three participating cement companies $\mathrm{KA}, \mathrm{KB}$ and $\mathrm{TC}$.

\begin{tabular}{|c|c|c|c|}
\hline HPO FACTORS & KA & $\mathbf{K B}$ & TC \\
\hline \multicolumn{4}{|l|}{ Continuous Improvement and Renewal } \\
\hline $\begin{array}{l}\text { 1. The organisation has adopted a strategy that sets it clearly apart from } \\
\text { other organisations }\end{array}$ & 6.4 & 8.0 & 7.4 \\
\hline 2. In the organisation processes are continuously improved. & 7.1 & 8.1 & 8.3 \\
\hline 3. In the organisation processes are continuously simplified. & 6.2 & 7.3 & 7.3 \\
\hline 4. In the organisation processes are continuously aligned. & 5.9 & 7.8 & 7.2 \\
\hline $\begin{array}{l}\text { 5. In the organisation everything that matters to performance is } \\
\text { explicitly reported. }\end{array}$ & 6.8 & 8.3 & 7.5 \\
\hline $\begin{array}{l}\text { 6. In the organisation both financial and non-financial information is } \\
\text { reported to organisational members. }\end{array}$ & 6.3 & 7.9 & 7.4 \\
\hline 7. The organisation continuously innovates its core competencies. & 6.2 & 8.1 & 7.3 \\
\hline $\begin{array}{l}\text { 8. The organisation continuously innovates its products, processes and } \\
\text { services. }\end{array}$ & 6.1 & 8.3 & 7.5 \\
\hline \multicolumn{4}{|l|}{ Openness and Action Orientation } \\
\hline 9. Management frequently engages in a dialogue with employees. & 5.6 & 7.9 & 6.9 \\
\hline $\begin{array}{l}\text { 10. Organisational members spend much time on communication, } \\
\text { knowledge exchange and learning. }\end{array}$ & 5.1 & 7.1 & 6.6 \\
\hline $\begin{array}{l}\text { 11. Organisational members are always involved in important } \\
\text { processes. }\end{array}$ & 6.0 & 8.0 & 7.1 \\
\hline 12. Management allows making mistakes. & 4.6 & 5.9 & 3.9 \\
\hline 13. Management welcomes change. & 6.4 & 8.3 & 7.4 \\
\hline 14. The organisation is performance driven. & 7.0 & 8.5 & 7.9 \\
\hline
\end{tabular}

International Journal of Management and Applied Research, 2020, Vol. 7, No. 4 


\section{Management Quality}

15. Management is trusted by organisational members.

$\begin{array}{lll}6.2 & 8.6 & 7.1\end{array}$

16. Management has integrity.

$\begin{array}{lll}6.4 & 8.8 & 7.5\end{array}$

17. Management is a role model for organisational members.

$\begin{array}{lll}6.3 & 8.2 & 7.2\end{array}$

18. Management applies fast decision making.

$\begin{array}{lll}5.4 & 8.3 & 6.9\end{array}$

19. Management applies fast action taking.

$\begin{array}{lll}5.5 & 7.9 & 6.8\end{array}$

20. Management coaches organisational members to achieve better results.

$\begin{array}{lll}6.4 & 8.0 & 7.6\end{array}$

21. Management focuses on achieving results.

$\begin{array}{lll}7.3 & 8.6 & 7.9\end{array}$

22. Management is very effective.

$\begin{array}{lll}6.3 & 8.2 & 7.3\end{array}$

23. Management applies strong leadership.

$\begin{array}{lll}6.5 & 8.3 & 7.2\end{array}$

24. Management is confident.

$\begin{array}{lll}6.8 & 8.9 & 7.3\end{array}$

25. Management is decisive with regard to non-performers.

$\begin{array}{lll}5.3 & 7.3 & 6.6\end{array}$

Employee Quality

26. Management always holds organisational members responsible for their results.

27. Management inspires organisational members to accomplish extraordinary results.

$\begin{array}{lll}6.5 & 8.1 & 8.0\end{array}$

28. Organisational members are trained to be resilient and flexible.

$6.2 \quad 7.8 \quad 7.6$

29. The organisation has a diverse and complementary workforce.

Long-Term Commitment

30. The organisation maintains good and long-term relationships with all stakeholders.

$\begin{array}{lll}5.9 & 8.0 & 7.2\end{array}$

$\begin{array}{lll}7.4 & 8.3 & 7.2\end{array}$

31. The organisation is aimed at servicing the customers as best as possible.

32. The organisation grows through partnerships with suppliers and/or customers.

33. Management has been with the company for a long time.

$\begin{array}{lll}7.6 & 8.6 & 7.8\end{array}$

$\begin{array}{lll}7.5 & 8.8 & 8.1\end{array}$

$\begin{array}{lll}7.9 & 8.8 & 8.3\end{array}$

$\begin{array}{lll}5.9 & 8.7 & 7.3\end{array}$

34. The organisation is a secure workplace for organisational members. $\quad \begin{array}{llll}5.1 & 7.6 & 7.1\end{array}$

$\begin{array}{lllll}\text { 35. New management is promoted from within the organisation. } & 7.0 & 8.4 & 7.5\end{array}$

International Journal of Management and Applied Research, 2020, Vol. 7, No. 4 